\title{
The Influence of Heating-up and Rapid Cooling on an Axially Restrained Steel Column in Fire
}

\author{
Yunchun XIA \\ School of Civil Engineering \\ Anhui Jianzhu University \\ Hefei, China \\ e-mail: wxiayc@126.com
}

\author{
Zhengchao XU \\ School of Civil Engineering \\ Anhui Jianzhu University \\ Hefei City, China \\ e-mail: zxc87391258@163.com
}

\begin{abstract}
Heating-up and rapid cooling by spray water had a large impact on the mechanics and deformation behavior for an axially restrained steel column. During heating, the axial force of the restrained steel columns increased in linearly. During rapid cooling, its axial force rapidly decreased until zero, and then it increased until the peak, and the max axial force was about $16 \%$ larger than that produced at heating, and its max bending moment was about $20 \%$ lager than that produced at heating. Axially restrained stiffness had a negative affection for its bearing capacity. When the axial stiffness ratio was less than 0.05 , the buckling and failure temperature was relatively close, but when it was more than 0.05 , there was a significant difference between them. Rotationally restrained stiffness played a beneficial role in its stable bearing capacity in fire. When its rotational stiffness ratio was less than 0.4 , the rotational restrained stiffness had a large beneficial effect on its stability, but when the rotational stiffness ratio was more than 0.4 , this beneficial effect was relatively small.
\end{abstract}

Keywords-axially restrained steel column; heating up; rapid cooling; spray water; axial force

\section{INTRODUCTION}

In recent years, with the development of steel structure buildings in China, fire protection was becoming more and more prominent. To effectively prevent these steel structures from fire destruction, most of them were protected by spray water. Rapid cooling by spray water for steel structure at high temperature would produce a large temperature difference inside of the structure, and the structure would produce rapid contraction, that would cause very large local stress. Li Guoqiang $[1,6]$ had studied on the thermal and mechanical coupling rules of cooling in air for a restrained steel beam. Axial tension of beam increased with cooling rate, and the maximum axial force produced in cooling was mach larger than that in heating up. Xu xiaoling [2] had studied on the failure probability and response time when a steel component was cooled by spray water. Gardner and Bailey C.G et al [3-5,7-16] had analyzed the deformation and reaction force for structural steel in local fire, the plastic deformation could not be restored during heating up, the internal forces will be redistributed between all components after it yielded, the residual stress was much larger. But the above researches did not discuss on the mechanics and deformation during rapid cooling by spray water. In fact, once spray water could not controlled fire properly, parts of steel structure would produce very large stress and strain, and they were much larger than those during heating-up, sometimes they would exceed its yield strength, which would directly lead to parts of the structure damaged or failed.

\section{Physical Parameters At High Temperature}

\section{A. Yield Strength}

For structural steel, its yield strength decreased at high temperature [2]. At high temperature, its yield strength was used to be determined by nominal strain, and it was usually defined by the strength reduction factor. According to According to Euro-Code 3 and Euro-Code 4, the reduction factor $\eta_{\mathrm{T}}$ of yield strength at temperature $\mathrm{T}\left({ }^{\circ} \mathrm{C}\right)$ could be calculated according to the following equations:

$$
\eta_{T}=\frac{f_{y T}}{f_{y 0}}=\left\{\begin{array}{l}
1+\frac{T}{767 \ln (T / 1750)}, 0^{\circ} \mathrm{C} \leq T<600^{\circ} \mathrm{C} \\
\frac{108(1-T / 1000)}{T-440}, 600^{\circ} \mathrm{C} \leq T \leq 1000^{\circ} \mathrm{C}
\end{array}\right.
$$

Where, $f_{y 0}$ was the yield strength of structural steel at ambient temperature, $\mathrm{N} / \mathrm{mm}^{2} . f_{y T}$ was its yield strength at temperature $\mathrm{T}, \mathrm{N} / \mathrm{mm}^{2}$.

\section{B. Elastic Modulus}

The elastic modulus of structural steel decreases at high temperature. According to some test results conducted by Tongji University, its fitting equation was as follows [1]:

$$
\frac{E_{T}}{E_{0}}=\left\{\begin{array}{l}
\frac{7 T-4780}{6 T-4760}, 20^{\circ} \mathrm{C} \leq T<600^{\circ} \mathrm{C} \\
\frac{1000-T}{6 T-2800}, 600^{\circ} \mathrm{C} \leq T \leq 1000^{\circ} \mathrm{C}
\end{array}\right.
$$

Where, $\mathrm{E}_{\mathrm{T}}$ was the elastic modulus of steel beam at temperature $\mathrm{T}, \mathrm{E}_{0}$ was its elastic modulus at ambient temperature, $\mathrm{T}$ was its temperature. 


\section{Poisson's ratio}

At ambient temperature, Poisson's ratio, for all types of structural steel, was from 0.27 to 0.30 . In fact, temperature had little affection on its Poisson's ratio. Here, Poisson's ratio $v$ of structural steel was taken as 0.3 .

\section{Thermal Expansion Coefficient}

At high temperature, according to Euro-Code3 and EuroCode4, the thermal expansion coefficient $\beta$ of structural steel at temperature $\mathrm{T}\left({ }^{\circ} \mathrm{C}\right)$ could be expressed as the follow:

$$
\beta= \begin{cases}0.8 \times 10^{-8}(\mathrm{~T}-20)+1.2 \times 10^{-5} & , 20^{\circ} \mathrm{C} \leq T \leq 750^{\circ} \mathrm{C} \\ 0 & , 750^{\circ} \mathrm{C}<T \leq 860^{\circ} \mathrm{C} \\ 2.0 \times 10^{-5} & , 860^{\circ} \mathrm{C}<T \leq 1200^{\circ} \mathrm{C}(3)\end{cases}
$$

\section{E. Specific Capacity}

According to Euro-code3, the specific capacity of structural steel could be calculated according to the following equations:

$$
C_{s}= \begin{cases}425+7.73 \times 10^{-1} T \\ -1.69 \times 10^{-3} T^{2} & , 20{ }^{\circ} \mathrm{C} \leq T \leq 600^{\circ} \mathrm{C} \\ +2.22 \times 10^{-6} T^{3} & \\ 666-\frac{13002}{T-738} & , 600{ }^{\circ} \mathrm{C}<T \leq 735^{\circ} \mathrm{C} \\ 545+\frac{17820}{T-731} & , 735^{\circ} \mathrm{C}<T \leq 900{ }^{\circ} \mathrm{C} \\ 650 & , 900{ }^{\circ} \mathrm{C}<T \leq 1200{ }^{\circ} \mathrm{C}\end{cases}
$$

\section{F. Relation between Stress and Strain}

For structural steel, its stress-strain model mainly divided into piecewise linear model and the continuous curve model. According to Ramberg-Osgood model theory, the relations between stress and strain at different temperature could be expressed as follows [1]:

$$
\varepsilon_{\sigma}=\left\{\begin{array}{l}
\frac{\sigma}{E_{T}}+\frac{3}{7} \frac{f_{y T}}{E_{T}}\left(\frac{\sigma}{f_{y T}}\right)^{50}, 20^{\circ} \mathrm{C} \leq T \leq 80^{\circ} \mathrm{C} \\
\frac{\sigma}{E_{T}}+0.01\left(\frac{\sigma}{f_{y T}}\right)^{n}, 80^{\circ} \mathrm{C} \leq T \leq 800^{\circ} \mathrm{C}
\end{array}\right.
$$

Where, $\sigma$ was the sectional stress, $\mathrm{n}$ was the shape factor of its stress-strain curve at temperature $\mathrm{T}$.

\section{G. Temperature Change of Structural Steel in Rapid Cooling}

When structural steel at high temperature was rapidly cooled by spray water, its surface temperature was often calculated by a difference method instead of differential method, and its numerical solution was often found by the incremental method. According some relevant specifications, its temperature change could be calculated according to the following equation [2]:

$$
T(t+\Delta t)=\frac{B}{\rho_{s} \mathrm{C}_{s}}\left[T(t)-T_{w}(t)\right] \cdot \Delta t+T(t)
$$

Where, $T_{w}$ was the temperature of cooling water, $\Delta t$ was time step (Normally, $\Delta \mathrm{t} \leq 30 \mathrm{~s}$ ). $C_{s}$ was the specific capacity of structural steel, it was about $600 \mathrm{~J} /\left(\mathrm{kg} \cdot{ }^{\circ} \mathrm{C}\right), \rho_{s}$ was steel density; it was about $7850 \mathrm{~kg} / \mathrm{m}^{3}$. B was the combined heat transfer coefficient.

\section{H. Combined Heat Transfer Coefficient}

\section{1) Component with no coatings:}

When structural steel component had no coatings, its combined heat transfer coefficient B could be calculated according to the following equation [6]:

$$
B=\left(a_{c}+a_{r}\right) \frac{F}{V}
$$

Where, $a_{c}$ was convection heat transfer coefficient, $a_{r}$ was radiant heat transfer coefficient, $\mathrm{F}$ was the area of structural steel acted by fire at unit length, $\mathrm{V}$ was the volume of structural steel acted by fire at unit length.

At high temperature, radiant heat transfer coefficient $a_{r}$ could be calculated as follow:

$$
a_{r}=\frac{2.041}{T-T_{w}}\left[\left(\frac{T+273}{100}\right)^{4}-\left(\frac{T_{w}+273}{100}\right)^{4}\right]
$$

For the convention heat transfer coefficient $\mathrm{a}_{\mathrm{c}}$, it could be calculated according to the following methods:

a) For single round nozzle:

$$
\alpha_{\mathrm{c}}=\frac{\lambda_{s}}{r}\left[\begin{array}{l}
2 \operatorname{Re}_{D}^{0.5} \operatorname{Pr}^{0.42}\left(1+\frac{5}{1000} \operatorname{Re}_{D}^{0.55}\right)^{0.5} \\
\times \frac{1-1.1 \mathrm{D} / r}{1+0.1\left(\frac{H_{0}}{D}-6\right) \frac{D}{r}}
\end{array}\right]
$$

b) For Single Slit Nozzle:

$$
\alpha_{\mathrm{c}}=\frac{\lambda_{\mathrm{s}}}{r}\left[\frac{3.06}{x / b+H_{0} / b+2.78} \operatorname{Re}_{b}^{m} \operatorname{Pr}^{0.42}\right]
$$




$$
\begin{array}{r}
m=0.695-\left[\frac{x}{2 b}+\left(\frac{H_{0}}{2 b}\right)^{1.33}+3.06\right]^{-1} \\
\left\{\begin{array}{l}
\operatorname{Re}_{D}=\frac{u_{c} D}{v} \\
\operatorname{Re}_{b}=\frac{2 u_{c} b}{v}
\end{array}\right.
\end{array}
$$

Where, $D$ was the diameter of nozzle, $\lambda_{s}$ was the conductivity of structural steel, $H_{0}$ was the distance between nozzle and the surface of structural steel, $r$ was the cooling radius of steel structure, $u_{c}$ was the average speed of spray water, $b$ was the width of nozzle outlet, $x$ was the distance of nozzle outlet from stagnation point. $R e$ and $P r$ were the Renault number and Prandtl number at average temperature.

According to EURO-Code3, the conductivity $\lambda s$ could be calculated according to the following equation:

$$
\lambda_{s}= \begin{cases}54-3.33 \times 10^{-2} T & , 20 \leq T \leq 800^{\circ} \mathrm{C} \\ 27.3 & , 800 \leq T \leq 1000^{\circ} \mathrm{C}\end{cases}
$$

\section{2) Component with non-expansion coatings:}

When the steel component had non-expansion coatings, its combined heat transfer coefficient B could be calculated according to the following equation [6]:

$$
B=\frac{1}{1+\frac{\rho \cdot C \cdot d \cdot F_{i}}{2 \rho_{s} \cdot C_{s} \cdot V}} \cdot \frac{\lambda_{i}}{h_{t}} \cdot \frac{F_{i}}{V}
$$

Where, $C$ was the specific capacity of coatings, $\rho$ was coatings density, $h_{t}$ was the thickness of coatings, $F_{i}$ was the coatings surface area of unit length, $\lambda_{i}$ was the thermal conductivity of protective coatings at $600^{\circ} \mathrm{C}$ or the equivalent thermal conductivity.

\section{Bearing Capacity}

According to EURO-Code3, the yield load $\mathrm{N}_{\mathrm{b}}$ could be calculated according to equation (15).

$$
N_{b}=X_{f} A k_{y T} f_{y \mathrm{~T}} / \gamma_{m}
$$

Where, $A$ was the sectional area of the component, $k_{y T}$ was yield strength ratio at temperature $\mathrm{T}, f_{y T}$ was the yield strength at temperature $\mathrm{T}, \gamma_{m}$ was the partial factor of steel component, and here it was 1.0. $X_{f}$ was the stable factor; it could be calculated according to equations (16).

$$
\begin{gathered}
X_{f}=\frac{1}{\varphi_{T}+\sqrt{\varphi_{\mathrm{T}}^{2}+\lambda_{T}^{2}}} \\
\varphi_{T}=0.5\left(1+\alpha \lambda_{T}+\lambda_{T}^{2}\right) \\
\alpha=0.65 \sqrt{235 / f_{y T}}
\end{gathered}
$$

$$
\lambda_{T}=\lambda_{1}\left(k_{y T} / k_{E T}\right)^{0.5}
$$

Where, $k_{E T}$ was the elastic modulus ratio at temperature $\mathrm{T}$.

$$
\lambda_{1}=\frac{\lambda}{\pi} \sqrt{f_{y T} / E_{T}}
$$

Where, $\lambda$ was the slenderness of the column.

\section{CALCUlation Modeling}

For an axially restrained steel column, its calculation modeling was shown in Fig.1.

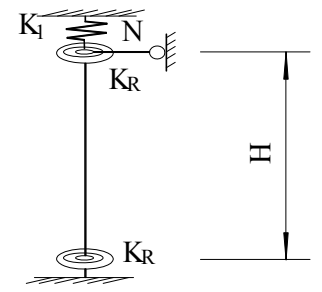

Figure 1. Sketch of loading for restrained column

Here, we supposed the rotational stiffness $K_{R}$ at both ends of the column was the same, and its axially stiffness ratio was $\beta_{1}$, its rotational stiffness ratio was $\beta_{R}$, its axial load was $N$. According to EURO-Code $3, \beta_{1}$ and $\beta_{R}$ could be calculated according to equation (21).

$$
\left\{\begin{array}{c}
\beta_{1}=\frac{k_{1}}{E_{0} A / H} \\
\beta_{R}=\frac{k_{R}}{4 E_{0} I / H}
\end{array}\right.
$$

Where, $k_{1}$ and $k_{R}$ were the axially restrained stiffness and the rotational restrained stiffness respectively; $E_{0} A / H$ and $4 E_{0} I / H$ were its axial stiffness and bending stiffness at ambient temperature respectively.

When the effect of axial load ratio $\mu_{N}$ and axially restrained stiffness $\beta_{1}$ were taken into account, the axial load $N$ could be calculated according to equation (22). 


$$
N=\left(1+\beta_{1}\right) \mu_{N} N_{b}
$$

Where, $N_{b}$ could be calculated according to equation (4), its temperature was the. Its plastic limit bending moment $M_{b}$ could be calculated according to the following equation:

$$
M_{b}=w_{p y} K_{y T} f_{y T} / \gamma_{m}
$$

Where, the subscript y indicated the strong axis $\mathrm{y}-\mathrm{y}, w_{p y}$ was the sectional plastic modulus.

\section{THE MECHANICS AND DEFORMATION}

Steel beam was made of Q235 H-type structural steel, its height was $3.0 \mathrm{~m}$, its yield strength $\mathrm{f}_{\mathrm{y} 0}$ was $235 \mathrm{MPa}$ at normal temperature, its elastic modulus $\mathrm{E}_{0}$ was $206 \mathrm{Gpa}$ (at $20^{\circ} \mathrm{C}$ ). Here, we thought that its temperature was uniform. Its temperature rising rate fit for ISO-834 standard during heating up, and according to some test results, the decrease rate of its temperature was shown in Fig.3.

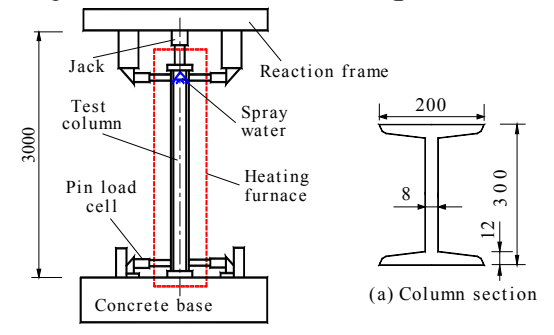

Figure 2. Sketches of test specimen

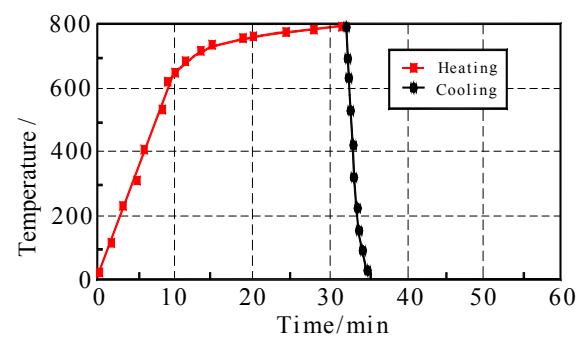

Figure 3. Temperature change during heating and cooling

\section{A. The Effect of Axial Load Ratio}

For an axially restrained steel column, its axial load ratio, slenderness and axial stiffness ratio would directly influence on its bearing capacity. When the slenderness $\lambda$ was 60 and its axial stiffness ratio $\beta_{1}=0.03$ and with no rotation, during heating and cooling by spray water, its mechanics and deformation was shown in Figure 4.

Before buckling, the axial force of restrained steel column increased linearly with its temperature rising at different axial load ratio. But after buckling, it rapidly reduced at first, and then it reduced slowly until with little change. During rapid cooling by spray water, its axial force rapidly decreased until zero, and then it increased until it reached the maximum, then it reduced until the column was cooled near ambient temperature, but the maximum axial force was over $16 \%$ larger than that produced in heating at the same conditions, and it was still very large when the column was cooled near ambient temperature.

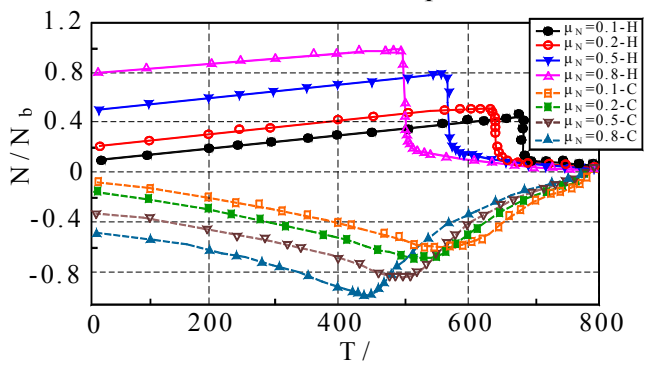

(a) Axial force

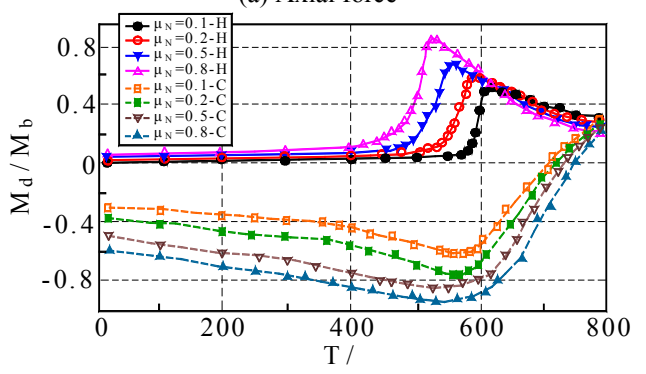

(b) Bending moment at mid-height

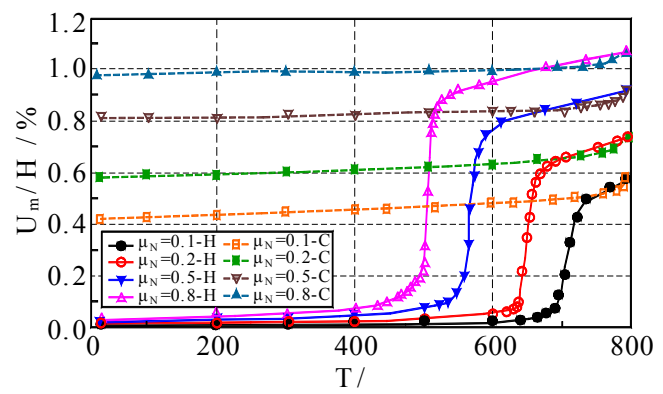

(c) Lateral displacement at mid-height

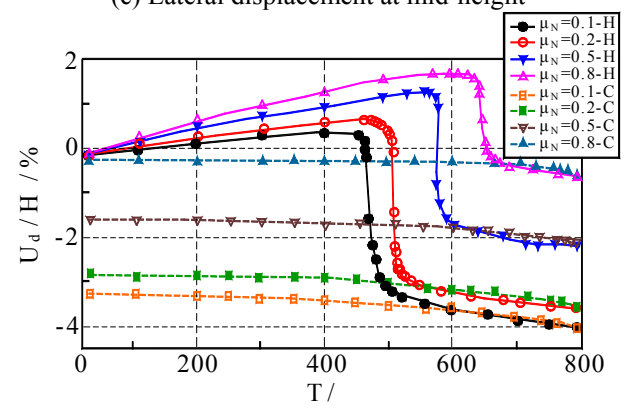

(d) Displacement at top end

Figure 4. Effects of axial load on the mechanics and deformation

At the early of heating, axial load ratio had almost no effect on its bending moment; it only increased about $15 \%$. But after buckling, its bending moment sharply increased until the peak, and its peak increased with axial load ratio. At the later heating (after yielded), its bending moment reduced, but it maintained very large. During rapid cooling, the bending moment reduced until zero, then it rapidly increased until the negative peak, and the max bending 
moment was $20 \%$ larger than the max bending moment produced during heating up. Then it reduced with its temperature drop until near ambient temperature, but it still kept at high level, and it was also much larger than that before heating.

At the early of heating, axial load ratio had almost no effect on the lateral displacement and axial displacement at top end of the column. But the lateral displacement sharply increased until it reached the maximum after the column buckled, and it reduced with the rising of axial load ratio. During rapid cooling, the lateral displacement had a little reduction, and its displacement at top end had a little recovered, but their reduction and recovery was very small, its lateral displacement reduced about $10 \sim 15 \%$ of the total lateral displacement, and its displacement at top end recovered about $6 \sim 10 \%$.

\section{B. Effect of Axially Restrained Stiffness}

For an axially restrained steel column, its axial constrain was produced by the around components. When the interaction between the components was taken into account, its slenderness $\lambda=60$, the axial load ratio $\mu_{N}=0.3$ and no rotation, the mechanics and deformation during heating up and rapid cooling by spray water was shown in Fig.5.

During heating-up and rapid cooling, the axially restrained stiffness ratio had a large effect on its axial force. When its temperature elevated, the axial force increased until the peak, but after buckling, its axial force rapidly decreased. During rapid cooling by spray water, its axial force dropt until zero at first, and then it increased rapidly until the peak, and the peak by cooling was over $15 \%$ larger than the peak in heating up, and their difference quickly increased with the decrease of load ratio.

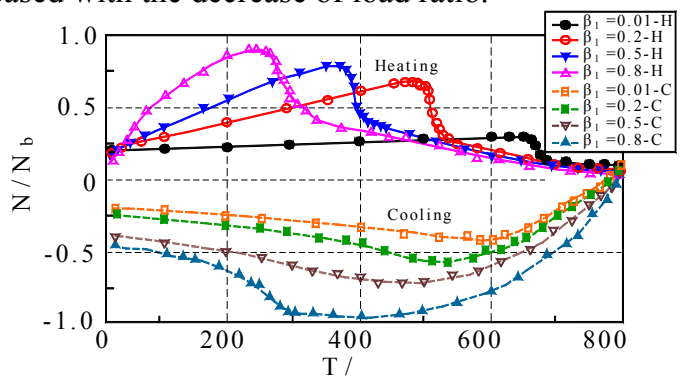

(a) Axial force

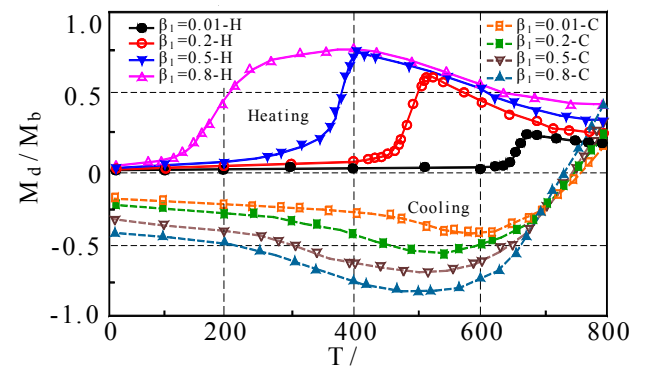

(b) Bending moment at mid-height

Figure 5. Effects of axially restrained stiffness on the mechanics and deformation

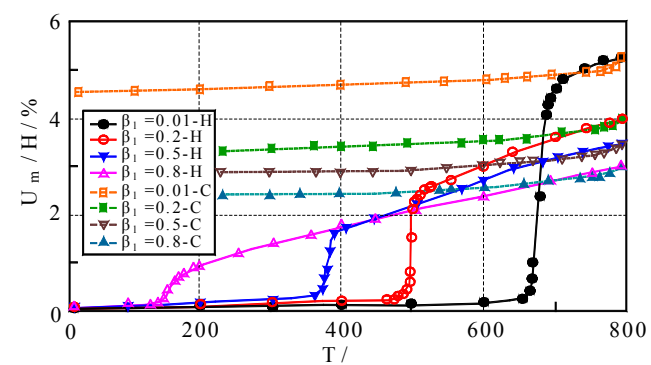

(c) Lateral displacement at mid-height

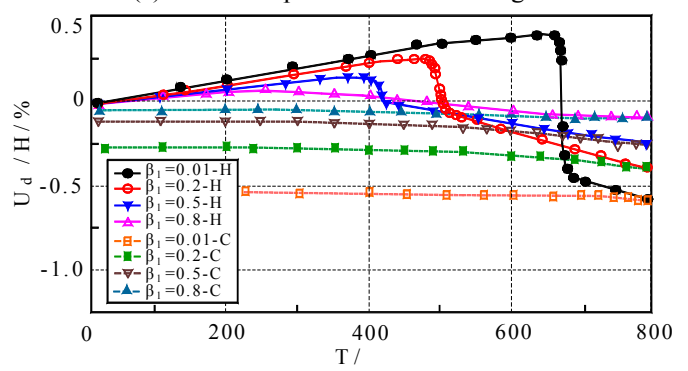

(d) Displacement at top end

Figure 5. Effects of axially restrained stiffness on the mechanics and deformation

At the early of heating up, its bending moment had an increasing trend, and the rising rate of bending moment increased with its axially restrained stiffness. When the steel column started to yield, its bending moment suddenly increased, and the peak of max bending moment also increased with its axially restrained stiffness. After the column yielded, its bending moment decreased at the similar rate under different axially restrained condition. During cooling, its bending moment reduced about $2 \sim 5 \%$ at first, and then it increased rapidly until the peak, and the peak during cooling was over $12 \%$ larger than the peak during heating up.

At the early of heating up, the effect of axially restrained stiffness on the displacement at top end was similar to the lateral displacement at its mid-height. When axial constrain increased, the max displacement at its top end decreased, and the temperature corresponding to the max displacement at top end was also smaller. After yielded, the lateral displacement at top end started to reduce, but the lateral displacement was very different at different axial load ratio, and its decreased rate was smaller when the axial load ratio increased.

\section{Effect of Rotational Stiffness Ratio}

For steel structure, its joint type of beam-to-column was different, but the rigid connection was rarely. In normally, the joint was between the hinged and rigid connection, that kind of joint could bear some bending moment besides the vertical shearing force. The angle between the axis-lines of beam and column had a little variation when the joint rotated and it was also restricted. So when the slenderness $\lambda=60$, axial load ratio $\mu_{\mathrm{N}}=0.3$ and axially stiffness ratio $\beta_{1}=0.2$, the mechanics and deformation during heating up and rapid cooling by spray water was shown in Fig.6. 


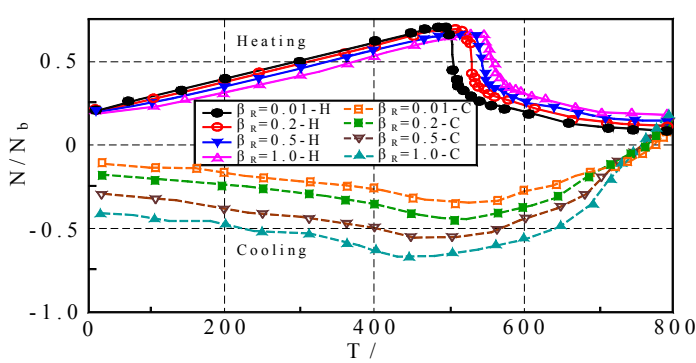

(a) Axial force

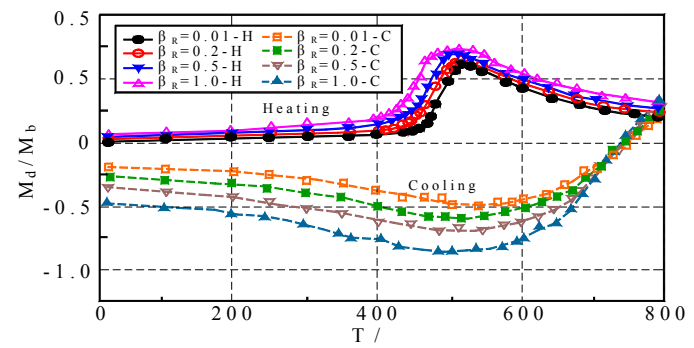

(b) Bending moment at mid-height

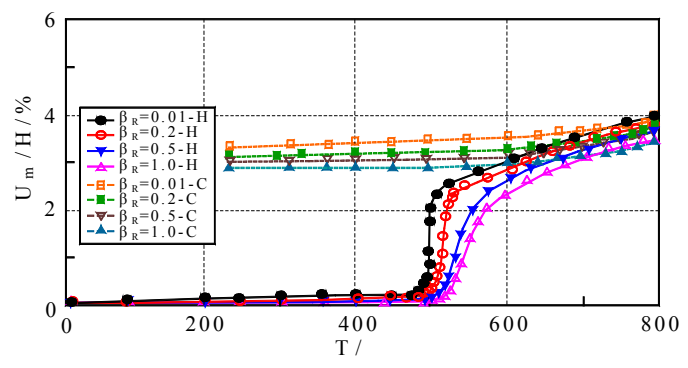

(c) Lateral displacement at mid-height

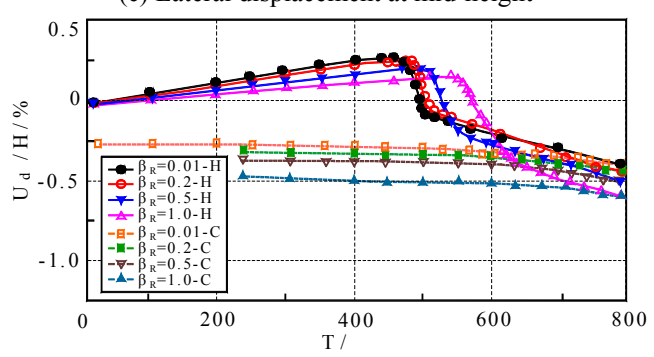

(d) Displacement at top end

Figure 6. Effects of rotational stiffness on the mechanics and deformation

For structural steel column, rotational restrained stiffness played a beneficial role in its stable bearing capacity in fire. When its rotational stiffness ratio was less than 0.4 , the rotational restrained stiffness had a large beneficial effect on its stability, but when the rotational stiffness ratio was more than 0.4 , this beneficial effect was relatively small.

When the column at high temperature was rapidly cooled, its axial force decreased until zero, and then it increased rapidly until the peak, then it reduced again until it was cooled to the ambient temperature, but it still maintained at high level. At the early of heating up, bending moment had an increasing trend. When rotational stiffness ratio was less than 0.5 , the rising rate of bending moment was larger. But after the steel column buckled, it bending moment increased sharply, and the corresponding max bending moment was larger when rotational stiffness was smaller. During cooling, its bending moment also reduced rapidly till to zero, and then it changed to increase quickly until the maximum, and the maximum was close to or more than the maximum bending produced in heating, then it decreased again until to be cooled to the ambient temperature, but the bending moment was much larger than those before heating up.

In the early heating, rotational stiffness ratio had almost no effect on its lateral displacement. For the column at weaker rotational stiffness, its lateral displacement became to increase at lower temperature. That showed the variation rules of axial force at different rotational stiffness ratio, which was the reason the rotational restriction was beneficial for the stability of steel columns in fire.

\section{CONCLUSIONS}

For the axially restrained steel column, during its heating-up and rapid cooling by spray water, its stable bearing capacity was affected by many factors, but they mainly included axial load, axially restrained stiffness and rotationally restrained stiffness. During heating up, at any axial load ratio, the axial force linearly increased with its temperature before buckling. The action of axial load could reduce its stable bearing capacity, and its yield and failure temperatures reduced with the rising of load ratio. Before buckled, the effect of axial load on the lateral displacement at mid-height was similar to that produced by initial bending moment.

Axially restrained stiffness had a great affection on the stable bearing capacity, and its effect was negative for its bearing capacity. When the axial stiffness ratio was less than 0.05 , the buckling and failure temperature was relatively close, but when it was more than 0.05 , there was a significant difference between the two temperatures, its failure temperature just changed very small. When there was only the axially restrained, its lateral displacement at midheight increased, but its critical temperature decreased significantly. At the early heating, the rising rate of increased with its axial stiffness. After buckled, axial stiffness had a great affection on its axial displacement.

Adversely from the axial stiffness, rotational stiffness was beneficial for the stable bearing capacity of restrained steel column at high temperature. When its rotational stiffness ratio was below 0.4 , the beneficial effect was very larger, but it was very small when its rotational stiffness ratio was larger than 0.4. After buckled, the lateral displacement at mid-height of the steel column increased with the decrease of rotational stiffness ratio at the same temperature, and the maximum axial displacement at top end of the column increased with the rising of rotational stiffness ratio, the temperature corresponding to the maximum axial displacement was also higher, the temperature at yield was also higher.

\section{ACKNOWLEDGMENT}

This work was financially supported by the National Natural Science Foundation of China (Grant No. 51478002). 


\section{REFERENCES}

[1] LI Guo-qiang, GUO Shi-xiong "Analysis of restrained steel beams subjected to temperature increasing and descending Part 1: Theory" Journal of Disaster Prevention and Mitigation Engineering, 2006(03): 242- 250.

[2] Yunchun XIA, "Damaged behavior of high temperature steel frame structure rapidly cooled by spray water in fire," Building Structure, vol.46, pp.583-590, 2016.

[3] L. Gardner, N.R. Baddoo, Fire testing and design of stainless steel structures, Journal of Constructional Steel Research, 2006, 62(6): 532-543.

[4] ECCS, European Recommendations for the Fire Safety of Construction Steel work, 2003.

[5] Y.C.Wang, J.M.Davies, "An experimental study of non-sway loaded and rotationally restrained steel beam assemblies under fire condition: analysis of test results and design calculations," Journal of Constructional Steel Research, vol.59, pp.291-296, 2003.

[6] Bailey, "Numerical modeling of structural fire behavior of restrained steel beam-beam assemblies using typical joint types," Engineering Structures, vol.32, pp.2337-2251, 2010.

[7] Hozjan T., Planinc I., "Buckling of an axially restrained steel beams under fire loading," International Journal of Structural Stability and Dynamics, vol.11, pp.451-456, 2011.

[8] Leonard Y Cooper, "The interaction of an isolated sprinkler spray and a two-layer compartment fire environment," International Journal of Heat and Mass Transfer, Vol.38, pp.1115-1126, 1995.
[9] Wang YC, Davies JM. “An experimental study of non-sway loaded and rotationally restrained steel column assemblies under fire condition: analysis of test results and design calculations," Journal of Constructional Steel Research, vol.59, pp.291-313, 2003.

[10] J.Janss and R. Minne, "Buckling of steel columns in fire conditions," Fire Safety Journal, vol.4, pp.227 -235, 1981.

[11] Poh KW, Bennetts ID, "Analysis of structural members under elevated temperature conditions," Journal of Structural Engineering ASCE, vol.121, pp.664-675,1995.

[12] Ali F, Shepherd P, Riindall M, "The effect of axially restrained on the fire resistance of steel columns," Journal of Constructional Steel Research, vol.46, pp.177-191,1998.

[13] Ali F, O'Connor D, "Structural performance of rotationally restrained steel columns in fire," Fire Safety Journal, vol.36, pp.679-691, 2001.

[14] Wang YC., "Post buckling behavior of axially restrained and axially loaded steel columns under fire conditions," Journal of Structural Engineering ASCE, vol.130, pp.371-381, 2004.

[15] Huang ZF, Tan KH, Ting SK, "Heating rate and boundary restrained effects on fire resistance of steel columns with creep," Engineering Structure, vol.28, pp.805-817,2005.

[16] Cai J, Feng J, "Thermal buckling of rotationally restrained steel columns," Journal of Constructional Steel Research, vol.66, pp.835$841,2010$. 